\title{
Postscript
}

\section{What We Have Learned about Learning to Read Talmud}

\section{Jon A. Levisohn}

What does it mean to "learn to read"? Typically, we think about learning to read simple texts in one's native language at an early age, in those societies and cultures that support universal literacy across all of their social classes. "Learning to read Talmud" is more than a special case of this general phenomenon; it is an enterprise that is dramatically different in significant ways. Even for native Hebrew speakers, the language of the Talmud is_-or more precisely, the languages are-foreign. The syntax is challenging, the issues sometimes obscure, the logic often torturous. In the general case of "learning to read," it typically happens for most people (although of course not all) in literate societies with gentle interventions by parents and educators. In the specific case of learning to read Talmud, it happens only through the most strenuous efforts.

To be sure, there are still many people who learn to read Talmud at an early age. It would be fascinating to examine that process. How does it happen? What challenges do those children face? What are they actually able to do and at what point? But the studies in this book focus on a different demographic, the "emerging adult" (or sometimes slightly older student). How does that population learn to read Talmud in colleges and seminaries? Some of the students whom we meet in these chapters have had significant experience with Talmud, such as Berkowitz's students at Barnard and Tucker's students at Mechon Hadar. Some have had less extensive experience, such as Kanarek's students at Hebrew College, Milgram's and Lehman's students at Jewish Theological Seminary and Lev's students at the Conservative Yeshiva. Others have had little or no experience, such as Gardner's students at the University of British Columbia and Alexander's students at the University of Virginia. All, however, are engaged in the process of "learning to read 
Talmud." Even more importantly, their instructors-the authors of the cases above-are uncommonly creative, reflective, and inquisitive about the process.

This concluding chapter will look across the eight cases of learning to read Talmud to see what we might learn about some of the central questions. What do we mean by reading Talmud? What is encompassed by the term, and why? What are the hallmarks or models of "learning" in this particular domain? But before those questions, we will consider an even more primary question: What is Talmud?

\section{What is Talmud?}

The question is not merely conceptual or historiographical but rather very concrete. What, in these cases, is this thing we call Talmud, which is the object of study? When we think about learning to read this text, what is the text that we have in mind? The answer might seem obvious: typically, "the Talmud" refers to the Babylonian Talmud, a set of 37 tractates of Jewish law, stories, interpretation, and wisdom, edited from around the third to seventh centuries in Iraq. Actually, however, the answer is anything but obvious. For example, none of the contributors to this volume recommend starting at the beginning of the Talmud and then simply proceeding through the text sequentially. That may be an appropriate practice for the semi-ritual mode of study known as dafyomi, but it is not a good way to learn to read. In fact, it is not even clear what "the beginning of the Talmud" even means. ${ }^{1}$

In educational terms, we might frame the issue in this way: the term "Talmud" refers to a text, to be sure, but it also refers to an educational subject or a field of study, as well as to a process. Learning to read Talmud is surely about learning to read a text, but it is also, at the same time, learning to engage in a particular "discipline." In this sense, learning to read Talmud

1 See the discussion in Charlotte Elisheva Fonrobert, "The Beginnings of Rabbinic Textuality: Women's Bodies and Paternal Knowledge," in Aryeh Cohen and Shaul Magid, eds., Beginning/Again: Toward a Hermeneutics of Jewish Texts (New York: Seven Bridges Press, 2002).

2 The scare quotes around "discipline" are meant to signal that there is, of course, no single methodology for the study of Talmud, nothing that we could readily identify as the "discipline" of Talmud. 
might be compared with, for example, learning to read poetry of the Romantic period. There is surely a text or a set of texts that one has in mind when one thinks of "Romantic poetry"- the poems of Wordsworth and Shelley and Keats. But learning to read these works is not a matter of beginning at the beginning and working one's way through the corpus. In fact, notably, "learning to read Romantic poetry" might be said to include the development of one's own understanding of what is within the corpus and what is not, as well as encountering a variety of representatives of that corpus.

When we think about defining fields or domains, we often focus on the boundaries. We look for a marginal case and try to decide if it is in the specified category or not. When we talk about reading Talmud, in some particular context, do we mean the Yerushalmi (the Jerusalem Talmud) as well as the Bavli (the Babylonian Talmud)? Do we mean commentaries as well as the text itself? Do we also implicitly include non-talmudic rabbinic works, such as Tosefta or midrashic collections? But the authors of the cases in this book tended not to pursue these questions. They took a different approach, one that is familiar from curriculum design: they focused on what texts are central and paradigmatic of the Talmud (or, as appropriate, the Mishnah). They defined Talmud for themselves and their students, implicitly, by presenting paradigms.

How? In several chapters, the paradigm is legal argumentation. Alexander, for example, writes about her "desire to equip students to make sense of the Talmud's overarching discursive framework," (p. 143) which she equates with the ability to "explain the back and forth of a complex dialectical argument" (p. 143). That is the paradigm for Talmud in this context, and the claim about paradigmatic status is made explicit. "By familiarizing them with dialectical interests, devices and movements that reappear throughout the Talmud, I am giving students tools to enter the Talmud's meandering conversations on any page" (p. 144). "Learning to read Talmud" means learning to make sense of those texts that include those dialectical moves and arguments. It is no surprise that her culminating exercise focuses on yeush shelo midaat, unconscious abandonment of an object; the talmudic discussion of this topic is a classic example of complex dialectical legal argumentation.

However, Gardner has a different view. In the specific setting in which he is teaching, focusing on teaching Talmud to graduate students in other academic fields such as classics or ancient history, he argues that it is more 
important to help these students learn to read rabbinic aggadah, not halakhah or midrash (pp. 122-124). ${ }^{3}$ The material is hard enough as it is without also introducing the technicalities of the legal or exegetical material. Narrative or non-legal material is better suited to give students an introduction that might enable their own subsequent, independent access to material that is relevant to their own research projects. "Learning to read Talmud," therefore, is learning to read talmudic narratives. In contrast to Alexander, then, Gardner would never turn to yeush shelo midaat as a paradigmatic text.

Nor is this issue limited to the subgenres of rabbinic literature, i.e., halakhah versus aggadah. Lev, in focusing on the teaching of a text as a "summons," offers a different paradigm that cuts across the halakhah/aggadah divide. Both halakhic and aggadic texts can be troublesome texts in the way that Lev describes. And since she is trying to get her students to read Talmud for self-reflection and personal growth, these texts are her paradigms. Lev would not deny that the Talmud also includes many non-controversial, non-problematic texts, of course, any more than Gardner would deny that the Talmud includes an awful lot of legal argumentation. But the question is not subject to quantification. In each of their particular contexts, the identification of paradigms - an implicit definition of what the Talmud is—is inseparable from the goals they have constructed for their students.

Lehman's case is particularly interesting in this regard. She begins from the observation that students enter her classroom with a particular conception of the relationship between the rabbis of the Mishnah and the priests of the Temple-a prior "understanding" that she wants to disrupt. This disruption becomes a focal point of her teaching. Now, this focal point is not the only criterion of selection for the mishnaic material that she chooses to teach in her

3 This is particularly notable since the setting-University of British Columbia, a large public university-would seem, initially, to be similar to Alexander's setting at the University of Virginia. But they develop radically divergent approaches to their teaching, due to the differences in their specific student enrollments (graduate students versus undergraduates) and their conceptions of the goals of those students (professional versus liberal education), as well as because of the differences in their own understanding of Talmud. Reading the two cases alongside each other makes this divergence abundantly clear. Yet, without these two cases, one might be forgiven for assuming that teaching Talmud at a large public university to students without prior experience would be a fairly homogeneous endeavor. 
class; she does not exclusively teach mishnayot that deal with the Temple. But surely those Temple-focused mishnayot—-both aggadic and halakhic —are paradigmatic in this pedagogic setting. If we ask, "What is the Mishnah in this context?" the answer is something like this: the Mishnah is a text that, paradigmatically if not universally, constructs and presents a relationship between its authors and the Temple rites. If, as a thought experiment, you have the opportunity to teach only one mishnah in this setting, the choice is clear: it ought to be a mishnah that displays this relationship in all its complexity.

Thus, regardless of the straightforward syntax of the phrase "learning to read Talmud," the Talmud is not a stable object that is just sitting and waiting for our attention. A book is not a curriculum, nor a subject or discipline. Once we undertake the effort to "curricularize" the Talmud, we operate from within a set of implicit or explicit commitments about our pedagogic purposes (or else we operate from within a set of unconscious or hidden assumptions about purposes). Those purposes then serve as criteria of selection, not just for appropriate teaching practices but for the material itself, the supposedly stable object of study.

\section{Reading Talmud: The Floor}

In reading across these cases, it is apparent that almost all of the authors emphasize accuracy and precision as the minimum requirements for competent reading of Talmud - the "floor" as opposed to the "ceiling." They want students to punctuate sentences accurately, to translate verbs precisely, to identify biblical verses correctly, to distinguish layers of argumentation astutely, to explain rabbinic concepts exactly, and to describe the function of technical terminology carefully. Berkowitz, for example, creates elaborate study guides to structure her students' careful translation and explanation of grammatical forms and technical terms. Kanarek refers to her expectations that students learn to "punctuate and divide a sugya into its chronological layers ... translate and explicate a sugya's argument, and define [its] technical terms" (p. 59). ${ }^{4}$ And Milgram advances an argu-

4 Her case in this volume does not focus primarily on these aspects of reading Talmud, but rather focuses on the work that she does with students around secondary literature. However, in an earlier study of her teaching (in a different setting) — a study to which several of the authors have referred—she focuses on the central task of getting students to 
ment for oral recitation that is predicated on the value of accuracy and precision-including, he adds, correct and fluent pronunciation-as paramount educational goals (pp. 164-165). ${ }^{5}$

From a certain perspective, it is not particularly surprising that these authors care about accuracy and precision. After all, they are each academically trained scholars of Talmud themselves. As scholars, they are focused on the kind of reading that they themselves have been trained to do, which is now what they want their students to learn to do. But even if this is not surprising because of that biographical consideration, we might still consider the fact that, in the literature on literacy in general education, accuracy and precision are known to be both important and problematic. In more progressive circles, teachers refrain from imposing norms on either receptive or expressive language too severely; they are eager to encourage students' efforts at sense-making and expression, even if the details get mangled and the spelling gets creative. It is not that progressive educators believe that normative interpretation and normative expression are unimportant. Rather, they are confident that normative interpretation and normative expression will come, as students continue the work of learning to read and write. So why, we might wonder, is Talmud different? ${ }^{6}$

slow down in order to increase their accuracy and precision. See Jane Kanarek, "The Pedagogy of Slowing Down: Teaching Talmud in a Summer Kollel," Teaching Theology and Religion 13, no. 1 (January 2010): 15-34; reprinted as "The Pedagogy of Slowing Down: Teaching Talmud in a Summer Kolel," in Turn It and Turn It Again: Studies in the Teaching and Learning of Classical Jewish Texts, ed. Jon A. Levisohn and Susan P. Fendrick (Boston: Academic Studies Press, 2013).

5 Gardner is a partial exception to the generalization about accuracy and precision; given his focus on narratives, he does not emphasize these aspects, at least in the case as he presents it. A more interesting example, however, is Lev. On the one hand, she does explicitly mention her concern for accuracy and precision (p. 176), even as she also describes her moral-educational goals that go far beyond that (about which more below). But on the other hand, she also emphasizes the ambiguities of the text that are not easily overcome through precision and accuracy, and sometimes turns the question of translation into an opportunity for exploratory interpretive discussion - without necessarily aiming to resolve the ambiguity.

6 Douglas (Dov) Lerea, in his 2012 dissertation, "What Do I Do Next? Teaching an Ancient Text by Listening to What Students Say: A Case Study of Pedagogic Dilemmas," is an excellent example within the field of Talmud pedagogy of a very different view, that emphasizes attention on students' sense-making, even when — or especially when - they are getting it wrong by conventional standards. 
To ground this question, consider Berkowitz's discussion of her use of study guides to help her students at Barnard learn to read Talmud. She notes that, when she arrived at Barnard, she discovered students who had strong backgrounds in Talmud from their experience in Jewish day schools and Israeli yeshivot and seminaries. But this was not necessarily a good thing. She writes:

All this familiarity, however, was precisely the problem. They had enough information to try to fill in the gaps in their understanding, so much so that they stopped being aware of those gaps (p. 5).

These students then had a great deal of trouble with the kind of patient decoding that she expected of them. In order to help them learn to read, she had to slow them down, to disrupt the hasty sense-making that they were accustomed to. So, the answer to the question of why one should focus on accuracy and precision is clear: students are getting things wrong. They are misreading.

But still, we might wonder what's wrong with misreading. After all, cannot we say that the rabbis themselves were masterful misreaders of prior texts? Are not midrashic exegeses replete with creative misreadings of biblical texts? Do not the editors of the Talmud misread earlier rabbinic statements in their work of stitching together a coherent discussion of whatever topic is at hand? Does not later Jewish tradition, likewise, demonstrate brilliant misreadings of prior sources in pursuit of spiritual or existential meaning? Can we ever really be clear about the dividing line between reading and misreading?

One response here is to suggest that the rabbis, when they adopted alternative interpretive strategies, were aware that they were doing something other than identifying the peshat (plain-sense interpretation). They were in the business of derash. ${ }^{7}$ What the authors of the cases in this book are concerned about,

7 As Kanarek notes (J. Kanarek, pers. comm.), Michael Fishbane describes derash as follows: "Here the ancient sages ... pondered the meaning of Scripture and discovered there theological, historical, and ethical matters reflective of their religious values and worldview. Here too was the closest reading of the words and phrases of the Bible, discovering new and striking meaning by comparing the words in one passage with those in another. For students of derash, the context of meaning is Scripture as a whole" (Michael Fishbane, "Introduction to Commentary," The JPS Bible Commentary: Song of Songs, JPS, 
on the other hand, is not intentional misreading but rather unintentional misreading — not the addition of creative interpretation, but the substitution of an incorrect meaning for an accurate one. This is not the place to enter into a discussion of what the rabbis knew and when they knew it, nor a place to debate to what extent their creativity was a product of conscious efforts at interpretive innovation or was a product of a system of reading that simply operated by different norms - all questions on which there is significant scholarly debate. What we can say, however, is that for these instructors, in these cases, consciousness is clearly an important goal.

Furthermore, it may be helpful to notice a particular feature of what we might call the phenomenology of misreading, which is that there is a kind of directionality to our reading processes: once we learn the accurate translation of a term or the precise parsing of a verb, we cannot go back. We have lost our innocence, as it were. The point is not that we never forget our grammar, which of course is untrue. Rather, the point is that, in the standard case, what was once a reading now becomes a misreading, or perhaps, what was once an unconscious misreading now becomes a conscious misreading. In this way, the norms of accuracy and precision are unlike other, contextspecific interpretational norms. We can read a text as structuralists on Monday and then come back on Tuesday and read the same text afresh as feminist critics, without constraint. We can read for halakhic implications on Monday and then come back on Tuesday and read the same text for its mystical connotations. But when someone points out that we have incorrectly parsed a verb on Monday, our option on Tuesday is restricted by that knowledge: we can only consciously misread, rather than doing so unconsciously.

Returning to Berkowitz, we might now notice that she has already emphasized this consciousness as central to the interpretive process:

When the students face the question ... of whether to insert brackets or parentheses into their translations, when they consider whether a passive participle is an adjective or a verb, when they decide exactly how to label a line of Gemara - they are making interpretive choices akin to choices made within the Talmud when its authors encountered their inherited traditions,

2015, p. xxxvi). Kanarek argues, further, that the correct term for the rabbis' efforts is not "misreading" but rather "rereading." 
and like all the Talmud commentators who faced the same questions that the students and I face in our classrooms today. (p. 26).

Accuracy and precision is the locus for interpretive choice-making. Emphasizing accuracy and precision is a way of bringing the interpretive process to consciousness, adopting a metacognitive stance toward one's learning (we will return to this point later on).

Before moving on from this discussion of accuracy and precision, however, we should note that, for Berkowitz at least, the emphasis on accuracy and precision generates a pedagogic problem. She explains that her effort to slow down the students succeeds too well: "The students stop making sense so enthusiastically ... that they forget the ultimate goal, which is to make sense of the passage as a whole" (p. 14). The students in her class embrace the work of precision and accuracy, and, as a result, they begin to think about texts as technical problems to be solved. In a pattern familiar from other educational arenas, attention to "the basics" backfires, with the outcome that the students are in danger of never getting beyond the basics.

The challenge, then, is this: How can the conscientious instructor emphasize accuracy and precision, while also making space for the bigger and bolder project of sense-making? How can one help to establish the floor for reading Talmud, while also constructing the aspirational ceiling? This is not the kind of question that is susceptible to an easy answer. In fact, it is not susceptible to an answer at all-it is a tension to be managed, not a problem to be solved.

\section{Reading Talmud: The Ceiling}

Each of the authors in this volume struggles with this pedagogic tensionbetween establishing the floor and encouraging students to reach for a more aspirational version of reading Talmud-in her or his own way. We should therefore clarify a potential misunderstanding of the metaphor of "floor" and "ceiling," according to which the former is necessary and fundamental, while the latter is optional and aspirational. In fact, none of the authors believes this. Even Milgram, who presents us with a case of oral recitation as a pedagogy to support the development of accuracy and precision in reading Talmud, argues that oral recitation in Talmud, like in other domains of 
reading, "increase[s] general appreciation for the literature studied" (p. 169). ${ }^{8}$ So we need an aspirational ceiling, as part of the work of learning to read Talmud, as well as a floor. But what exactly is that ceiling? How can we conceptualize the broad range of skills or stances encompassed by reading Talmud?

Alexander, in her case, explains that some of her students come to understand that reading Talmud is not like reading a textbook. The words of one student demonstrate this broader view:

When it comes to Talmud study, the point is to interact with the Torah in a special way, to see the beauty in many different perspectives, and to understand the thought processes involved in arriving at those perspectives (p. 153).

What this student is proposing, and the stance toward the text that Alexander is trying to cultivate, is that reading Talmud is a matter of context-sensitive encounters (with biblical texts and with the rabbinic interpretations of those texts) more than the acquisition of knowledge. That is why standard reading strategies_-skimming, summarizing — are so unhelpful. Precision and accuracy are necessary, to be sure, but so is openness to the encounter and a willingness to explore multiple interpretive possibilities.

Others think about the ceiling differently; indeed, while there are points of contact, each case has a ceiling distinct from every other. For Lehman, students should develop a certain kind of hermeneutics of suspicion about the "polemical impulses at work on the part of the authors of the texts that they were reading" (p. 94); "reading the Mishnah was intimately connected to being suspicious of [the students'] prior views" (p. 106), rather than taking the claims of the Mishnah at face value. Lev, for her part, explicitly declares that her efforts to "work the heart" emerge from her sense that teaching for precision and accuracy is not enough (p. 176). This means, first, that students should learn to recognize multiple possible readings of the same talmudic phrase, and second, that students should learn to engage in moral exploration and develop increased self-understanding — while they struggle with the meaning of the text.

8 He quotes a student who reports that "reading the text aloud ... highlights the very nature of the Talmud and, by extension, Talmud study" (p. 169). 
For Tucker, on the other hand, reading Talmud encompasses the ability to discern not the morally problematic aspects of a sugya, but rather, the textually problematic aspects. For Kanarek, reading Talmud includes reading secondary material on Talmud, to be able to engage with scholarship on Talmud productively_not just for the sake of scholarly competence but in order to gain an awareness of ambiguity and subtext, "connecting a sugya to a wider world of ideas" (p. 57), and more. For Berkowitz, students should be able to "consider ... the Talmud as an intellectual, cultural and religious project” (p. 22). For Gardner, reading Talmud means, especially, accessing the talmudic material that is particularly relevant to whatever a student's scholarly interests happen to be, to be able to access Talmud as an intellectual resource.

When considering this diverse, robust set of reading practices, we may find ourselves mystified. How can it be that "learning to read Talmud" encompasses all this? And if it does, then how does anyone ever succeed in this enterprise? But, on reflection, all these practices are consonant with practices in other domains as well. Learning to read historical texts means, among other things, learning how to critique the moral stances within the texts, while also recognizing the differences in the moral standards of other (historical) cultures. Learning to read scientific literature also means, among other things, learning how to draw on those studies to support or challenge one's own scholarly project. Reading is never simply a decoding of sounds. It is never simply an exercise in translation. To read is to make meaning, and the meaning that one seeks is always a function not just of the text but also of the situation in which one finds oneself and the reasons that one has opened up the text to begin with.

\section{Metacognition}

If we were to ask about the hallmarks of learning in this domain, the evidence of these eight cases suggests, first, the importance of what educational researchers and psychologists call metacognition-higher-order reflection on one's own mental processes, or "thinking about thinking." The authors of these cases, in developing their own pedagogies, have independently arrived at the conviction that their students will learn to read better if they can help them to 
reflect on their reading, to think about what they're doing as they're doing it (or soon after they've done it). Berkowitz writes about "sensitiz[ing] the students to their own process of sense-making ... and encourag[ing] them to reflect on the project of translation and how making sense works differently in different languages" (p. 17). Tucker encourages students to articulate systematically all the problems that they experience in the text. Alexander assigns a set of reflections that provide a scaffolding for metacognition, "to draw students' attention to various aspects of the reading experience so that they could reflect on which strategies they found to be more effective and which less so" (p. 139). A student reports that Gardner "continuously provok[es] the students to think while we are reading," a strategy that Gardner connects to research on schema-activation among proficient readers in general education (p. 125).

The conviction about the importance of metacognition as an aid to learning is not derived from a careful review of the scholarly literature on the subject, even though there is much scholarly literature that supports precisely that conviction. ${ }^{9}$ Instead, we might speculate that this conviction derives from the nature of the subject matter, which has been explicitly structured as a learning-how task rather than a learning-that task, so that reflection seems like an appropriate cognitive complement to the "practical" side. In addition, this conviction about metacognition may derive from the nature of these specific contexts, involving learners who are adults, so that reflection seems like something that they ought to be able to do, but who are also relative novices, so reflection seems like something that they need to do. These instructors, in other words, may not be as committed to metacognition in other kinds of teaching they do (a Jewish history survey course, for example). And other instructors, who teach Talmud to younger students, might not be as committed to metacognition as these instructors in higher education classrooms, because they might not intuit that younger students are as open to or as capable of metacognition as adults. Moreover, the literature on metacognition confirms that not all metacognition is a good thing: if you are trying to learn how to ride a bike or to speak a language, it is not clear that spending a lot of time reflecting on the process is really all that helpful.

9 See, for example, discussions in John D. Bransford, Ann L. Brown, and Rodney R. Cocking, eds., How People Learn: Brain, Mind, Experience and School (Washington, D.C.: National Academy Press, 2000). 
Nevertheless, the consistent presence of metacognition across these cases is surely significant. In fact, the cases demonstrate more than just a shared conviction among the instructors about its importance. They also demonstrate a variety of pedagogic practices - specific techniques - that these instructors have developed to promote what is sometimes called a "culture of metacognition" in their classrooms. On the evidence of these cases, learning to read Talmud in these settings proceeds, at least in part, through the involvement of reflection on what is happening in the text, on what the textual or other difficulties are, and on what one does as one struggles to make meaning.

\section{Competing Models of Learning}

How do we conceptualize the development of knowledge in this domain? The eight cases suggest a tension between two competing models. On the one hand, in several, the scholars write about building up understanding bit by bit, slowly accumulating the individual pieces until the students arrive at the point of understanding the whole sugya. We might call this the "building-block" model, and notice that it seems to cohere with the emphasis on precision and accuracy mentioned earlier. On the other hand, there's another model, a version of the hermeneutic circle: in this model, the students move back and forth between some understanding of the whole that informs their understanding of the individual parts and an understanding of the individual parts that informs their revised understanding of the whole.

As an example of the building-block model, consider Alexander's description of the way in which her students begin with "the tendency to gloss over details in the hope of stabilizing meaning by detecting an overarching narrative" (p. 146). They try to skim the text, looking for the big picture. But that strategy, which works well in other kinds of academic reading, is disastrous when it comes to Talmud. Instead, her students have to learn a new approach, a much more patient approach, one that understands words and phrases and sentences, step-by-step through reading and re-reading, cautiously moving forward only when their understanding of the prior sentence has been solidified. 
Gardner represents a different instance of the building-block model. For him, the building blocks are not the words and phrases of the rabbinic sugya. Rather, he conceptualizes the building blocks as the background knowledge that must first be in place in order to make sense of the text. "Before teaching Talmud," he writes, "it is first necessary to teach about Talmud" (p. 121), to explain to students why the text is important and to provide an overview of the genre in which the students can situate the texts they encounter. ${ }^{10}$

However, other contributors lean toward the hermeneutic-circle model. Tucker, for example, argues that the "first phase of interpretation is nothing less than taking responsibility for the logical coherence of the sugya [as a whole]" (p. 38). This is a striking formulation. Tucker is concerned that the students should practice an ethic of responsibility in their learning, recognizing and enacting this responsibility from their earliest encounter with the sugya. He does so in order to avoid the situation that Berkowitz describes in her classroom, namely, the situation in which students focus so intently on getting the building blocks right that they lose sight of the goal of making sense of the sugya. Notably, Tucker claims that the enactment of this responsibility "throws them into addressing any gaps in their knowledge by precisely defining words, identifying key legal terms, and sharpening the logic of the passage" (p. 38). That is, for Tucker, the big-picture understanding operates in tandem with the technical details — from the very first moments of encounter with the sugya. ${ }^{11}$

Kanarek's focus on integrating secondary material may also be seen as a kind of hermeneutic-circle model. Where some might argue that learning to read scholarship on Talmud should wait until students learn to read Talmud itself, Kanarek adopts a different, more integrated view: what students learn from the scholarship extends or deepens their ability to read the text. To take just one example from several in her case, the scholarly literature helps her student James "to read the range of interpretive possibilities latent in the sugya"

10 Notably, Alexander describes her own movement away from this stance. Whereas her prior approach focused on first teaching about the Talmud's relevance to motivate the students' learning, she now seeks to generate motivation by a greater emphasis on metacognition (pp. 137-139).

11 In his chapter in this volume, Tucker chooses not to document or explore how this actually happens; his focus is elsewhere. So we must take his claim as an intriguing hypothesis that deserves further investigation. How and in what ways do students (of any age) move from part to whole on a moment-by-moment basis as they encounter a rabbinic text? Such a study would make an enormous contribution to the field of rabbinics education. 
(p. 84). ${ }^{12}$ Thus, there is, at least in some instances, a back-and-forth dynamic between the secondary material and the primary encounter with the sugya.

Of course, this issue is not entirely unique to reading Talmud. If sensemaking in general follows the hermeneutic circle-if we always approach a text or the world with what Heidegger called "fore-structures," provisional understandings of the whole that get refined as we encounter the partsthen reading Talmud should follow the same general pattern. Yet, we could make a reasonable argument that Talmud is a special case, of sorts, because of the difficulty and complexity of the texts that comprise it. So even if it is true that, at some abstract level, the work of reading Talmud can be described in the same hermeneutic terms-even if it is true that we approach a sugya with some anticipations regarding its meaning and its structure-it may also be true that the experience of reading Talmud feels a lot more like the cautious and painstaking assembling of brick upon brick. As a matter of pedagogy, learning to read Talmud may include the development of a certain disposition of patience, the ability to control one's frustration when the whole does not yet make sense while one attends to the meaning of individual terms —even as one also, as Tucker argues, accepts "responsibility for the logical coherence of the sugya [as a whole].”

\section{Conclusion: What We Need to Learn Now}

The eight cases in this volume represent an unprecedented set of windows into university and seminary classrooms where Talmud is taught and learned. The authors have shared their pedagogic practice with courage and insight, and with an impressive commitment to ground their analyses in empirical data, drawn from teaching journals, student work, classroom discourse, student evaluations, and other materials. ${ }^{13}$ Moreover, the clarity of their shared focus on "learning to read Talmud" allows for generative comparisons, and illumi-

12 In Lehman's case, while the encounter with secondary material is not as central a focus as it is for Kanarek, she too writes that she "want[s] the students to learn to move from primary to secondary sources and back to primary sources" (p. 110).

13 This is not the place for a discussion of the methodologies at work in these cases. Readers of the individual chapters will note that some are more systematic and some more exploratory. What is important, however, is that the claims that they make are appropriate to the evidence that they have gathered. 
nates the deep diversity encompassed by that deceptively simple phrase. It is also particularly praiseworthy that the authors share with us examples not just of what it looks like when students read well, but sometimes what it looks like when they do not (see, for example, Berkowitz's student, who does a poor job on the study guide, or Lehman's example of a student who seems to revert to her prior assumptions under the pressure of the final exam).

In looking across these cases and seeing what we are able to learn from them, we can also envision the next stage of research on Talmud pedagogy. The cases are like snapshots. Could the next stage of research resemble movies? We might investigate what learning to read Talmud looks like in the specific sense of a developmental process, in which a student, a reader, moves from non-understanding to understanding, or more globally, from illiteracy to literacy over time.

Imagine if we were able isolate specific component elements of learning to read Talmud and then observe how students become better at those particular skills or those particular dispositions-not just over the course of one semester, but over the course of several years. Imagine if we were able to develop, out of that data, an understanding of the typical or common challenges in reading Talmud and how they are overcome over time. Learning to read Talmud may never be susceptible to the kind of systematic analysis that has been accomplished in second-language acquisition, where scholars are able to define specific stages of learning in great detail, as well as to describe the standard trajectories of learning from one stage of proficiency to the next. But at the moment, we lack even the basic categories to describe the differences between novice and expert readers.

This observation, however, is merely an acknowledgement of what we still do not know and of the kind of research that we ought to develop. In the meantime, these authors have provided us with a rich, nuanced, interconnected set of windows into the practice of teaching Talmud, identifying many of the most important pedagogic tensions and challenges in this work. For that, we are in their debt. 